\title{
Response surface optimization of ultrasound assisted extraction (UAE) of phycocyanin from microalgae Spirulina platensis
}

\author{
H. Hadiyanto*, Suttrisnorhadi \\ Center of Biomass and Renewable Energy (CBIORE), Department of Chemical Engineering, Diponegoro University, Jl. Prof. Soedarto, \\ $\mathrm{SH}$-Tembalang, Semarang 50239 Indonesia
}

\section{A B S T R A C T}

\begin{abstract}
Phycocyanin extracted from Spirulina platenis has been linked to many food colorant and health applications. The extraction of this compound by using conventional method resulted low yield and longer processing time. This research was aimed to determine optimum process conditions of ultrasound assisted extraction (UAE) of phycocyanin compound from microalgae Spirulina platensis. The response surface methodology (RSM) was employed to search UAE optimum conditions among set of variables: temperature $\left(T=30-60^{\circ} \mathrm{C}\right)$, time (20-50 $\mathrm{min})$ and frequency $(28-42 \mathrm{kHz})$. The result showed that under unoptimized conditions, the yield of phycocyanin extracted by conventional method was $11.13 \%$ while ultrasound could increase the yield up to $13.61 \%$. The optimization by using RSM showed that

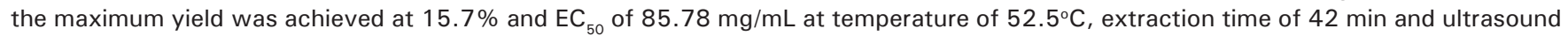
frequency of $42 \mathrm{kHz}$. The conclusion of this research was ultrasound could improve significantly the efficiency of extraction of phycocyanin from microalgae and the obtained optimal conditions can be potentially scaled up to isolate phycocyanin for large production in the food and pharmaceutical industries.
\end{abstract}

Keywords: Spirulina; Phycocyanin; Ultrasound; Extraction; Solvent

\section{INTRODUCTION}

Sustainable production of C-Phycoyanin (CPC) from algae Spirulina platensis has been intensively studied due to their outstanding benefits. The CPCis the pigment sources produced by the microalgae Spirulina platensis and contain $20 \%$ (d.b) of the cell protein (Oliveira et al., 2010). The CPC has been widely applied in the food, pharmaceutical, and cosmetic industries due to their unique antioxidant and anti-inflammatory properties (Kuddus et al., 2013). The extraction of CPC from Spirulina platensis can be performed by various methods, such as solvent extraction by maceration and soxhlet methods, however, these conventional techniques are time- and solvent consuming (Kadam et al., 2015; Hadiyanto et al., 2015). Moreover, the extraction using conventional method does not give pure and high yields and it uses large amount of solvents which are detrimental to human as well as environment (Shirsath et al., 2012; Setyoningrum et al., 2015).
In recent years, various novel extraction methods have been introduced for the extraction of active components from plants, such as ultrasonic-assisted extraction (UAE), supercritical fluid extraction and enzymatic extraction (Hardlei et al., 2007; Yang et al., 2009; Vinatoru, 2001; Sivansankari et al., 2014). Among these methods, the UAE is an efficient extraction technique due to shorter extraction time stimulated by its acoustic cavitation power. The ultrasound irradiation generates a mechanical effect which increase solvent penetration into the plant material and increase the contact between solvent and plant tissue which accelerate diffusion of extracted solid compound to the solvent (Rostagno et al., 2003). Therefore, the UAE has been widely employed to extract natural compounds, including extraction of phycocyanin (Hadiyanto et al., 2015; Setyoningrum et al., 2015), astaxanthin (Zou et al., 2013), $\beta$-carotene (Dey et al., 2013). Moreover, the ultrasound assisted extraction (UAE) is also recently considered as an efficient technique to extract low molecular weight

\footnotetext{
*Corresponding author:

H. Hadiyanto, Center of Biomass and Renewable Energy(CBIORE), Department of Chemical Engineering, Diponegoro University,

JI. Prof. Soedarto, SH-Tembalang, Semarang 50239, Indonesia. E-mail: hady.hadiyanto@gmail.com
} 
compounds and phytochemical from plant (Hromadkova et al., 2002), and is easily implemented for large industrial scale (Vinatoru, 2001; Vilkhu et al., 2008). However, the optimization of UAE extraction process of CPC is still hardly found especially to understand the effect of significant variables: UAE temperature, time and frequency.

Temperature is becoming an significant parameter in the phycocyanin extraction since it will affect pigment and protein contents in phycocyanin during processing and storage (Chaiklahan et al., 2012; Setyoningrum et al., 2015). The extraction process of temperatures above $80^{\circ} \mathrm{C}$ by using conventional extraction for 24 hours could damage the pigment phycocyanin and reduce the ability of antioxidant activity (Antelo et al.,2008). At higher temperature, phycocyanin structure will be destructed due to coagulation of phycobiliprotein (Sarada et al., 1999; Antelo et al., 2008). Besides temperature, the extraction time was also considered as important parameter for bioactive compound extraction (Kadam et al., 2015). Furthermore, Kadam et al.,(2015) showed that increasing the extraction time could gained more extracted bioactive compound from plant material, and it could be shortened by using ultrasound assisted extraction (UAE) method. In addition, UAE power has been investigated as the paramount parameter in the extraction of bioactive compound. Although there was a contradiction observation has been reported, however the UAE power still deserves as significant parameters affecting extraction efficiency. Vuong et al., (2015) observed that the UAE power has no positive effect to the efficiency of extraction, while Kadam et al., (2015) showed a contrary result, in which bioactive compound extraction will be positively affected by UAE power. Therefore, there is still important to search on their optimum conditions of these three important parameters with aim to gain higher extraction yield and antioxidant activities.

Response Surface Methodology (RSM) is a statistical method to determine a correlation between responses and set of input variables (Khuri and Mukhopadhyay, 2010). The RSM is time and cost effective tools to describe influences and interactions of input variables to the responses and to evaluate the key parameters (Box and Wilson, 1951; Wang et al., 2011). This research was aimed to investigate the effect of UAE variables: temperature, time and frequencies in extraction of phycocyanin from microalgae Spirulina sp and then to employee Response Surface Methodology (RSM) as a useful engineering tool to optimize process conditions in order to achieve high yield and high antioxidant activity. The UAE method for phycocyanin were studied at UAE frequency of $28-42 \mathrm{kHz}$, extraction time of $20-50 \mathrm{~min}$ and temperature of $30-60^{\circ} \mathrm{C}$. As the response variables were the extraction yield and antioxidant activity $\left(\mathrm{EC}_{50}\right)$.

\section{MATERIAL AND METHODS}

\section{Materials}

Microalgae Spirulina platensis biomass with 11\% moisture content (d.b) was kindly provided by CV. Neoalgae (Sukoharjo, Indonesia).

\section{Phycocyanin extraction using Ultrasound assisted extraction}

In this study, UAE extraction was carried out in an adjustable ultrasound bath with frequency of $28 \mathrm{kHz}$ to $42 \mathrm{kHz}$ and power of $200 \mathrm{~W}$ to determine the effect on the frequency of phycocyanin extract and natural antioxidants from microalgae Spirulina sp. The conventional extraction method was also used for comparison. The conventional extraction was done using ethanol solvent and 4 hrs extraction time. About 15 grams of biomass was dissolved in $250 \mathrm{~mL}$ of solvent. The biomass was then sonicated at defined frequencies in an ultrasound bath, under the set variables (UAE temperature, UAE time and UAE frequency). Samples were settled for 2 hours in an erlenmeyer coated with aluminium foil. The obtained supernatant was separated from the sediment and then was dehydrated in a rotary vacuum evaporator to separate the solvent in order to obtain phycocyanin extract. The concentration of phycocyanin was determined according to Bennet and Bogorad (1973):

$$
\mathrm{PC}=\frac{\left(\mathrm{OD}_{620}-0.474 \mathrm{OD}_{652}\right)}{5.34}
$$

Where PC is the phycocyanin concentration $(\mathrm{mg} / \mathrm{mL})$, $\mathrm{OD}_{620}$ is the optical density of the sample at $615 \mathrm{~nm}, \mathrm{OD}_{652}$ is the optical density of the sample at $652 \mathrm{~nm}$.

The yield of the extraction was defined as (Silveira et al., 2007):

Yield $(\% g / g)=\frac{P C \times V}{D B} \times 100 \%$

Where $\mathrm{V}$ is the solvent's volume $(\mathrm{mL}), \mathrm{DB}$ is the biomass (dry weight-g).

\section{Antioxidant activity determination}

The antioxidant activities in this research were indicated as $\mathrm{EC}_{50}$ values. The higher antioxidant activity will be indicated by lower $\mathrm{EC}_{50}$ values (Yeh et al., 2011). The antioxidant activity of all the extracts were measured by using a method described by Sen et al., (2005). About $23.5 \mathrm{mg}$ DPPH was dissolved in $100 \mathrm{~mL}$ methanol and then the solution was kept at $4^{\circ} \mathrm{C}$. For antioxidant activity measurement, the solution was diluted by 1:10 in methanol. Approximately $0.1 \mathrm{~mL}$ of the extract was added in to $3.9 \mathrm{~mL}$ of DPPH solution so $4 \mathrm{~mL}$ of total solution could be characterized 
by discoloration. A blank solution of phycocyanin was prepared by adding $0.1 \mathrm{~mL}$ pure phycocyanin to $3.9 \mathrm{~mL}$ methanol. After the reaction completed (4 hrs) at room temperature, the absorbance was measured at wavelength of $516 \mathrm{~nm}$ using spectrophotometer UV/VIS sp 300. Antioxidant activity of the extract solution was then calculated by using Equation 3:

$$
\mathrm{EC}_{50}=\frac{\text { abs. blank }- \text { abs. extract }}{\text { abs. blank }} \times 100 \%
$$

$\mathrm{EC}_{50}$ values represented the amount of the concentration of the extract solution needed to reduce DPPH free radicals by $50 \%$ (Yeh et al., 2011).

\section{Response surface methodology design}

In this study, the experimental design was based on a Box-Behnken construction which consists of 11 factorial experiments and 4 repeating central point variables. The UAE temperature $\left(\mathrm{X}_{1}\right)$, extraction time $\left(\mathrm{X}_{2}\right)$ and ultrasound frequency $\left(\mathrm{X}_{3}\right)$ were chosen as independent variables. The independent variables were set as temperature at 30,45 and $60^{\circ} \mathrm{C}$, extraction time at 20,35 and $50 \mathrm{~min}$, and ultrasound frequency at 28, 35, $42 \mathrm{kHz}$. The phycocyanin yield and $\mathrm{EC}_{50}$ were selected as the responses for the combination of these independent variables. In order to be evaluated in response surface methodology, the real value of independent variables must be transformed to the coded variables.

The independent variables and coded variables are shown in Table 1. To express the yield and EC ${ }^{50}$ of extracted phycocyanin as a function of set of independent variables, a second order polynomial equation was employed as follows (Vuong et al., 2011):

$$
Y=\beta_{0}+\sum_{i=1}^{k} \beta_{i} X_{i}+\sum_{\substack{i=1 \\ k<j}}^{k-1} \sum_{j=2}^{k} \beta_{i j} X_{i} X_{j}+\sum_{i=1}^{k} \beta_{i i} X_{i}^{2}
$$

Where $\mathrm{X}_{i}$ and $\mathrm{X}_{\text {are }}$ independent variables, $\mathrm{Y}$ is response variables, while $\beta_{\mathrm{o}}, \beta_{\mathrm{i}}, \beta_{\mathrm{iip}}, \beta_{\mathrm{ij}}$ are the regression coefficients and $\mathrm{k}$ is the number of variables.

In this study, the three independent variables were used: Temperature $\left(\mathrm{X}_{1}\right)$, extraction time $\left(\mathrm{X}_{2}\right)$, and Ultrasound frequency $\left(\mathrm{X}_{3}\right)$ and $\mathrm{Y}_{\mathrm{i}}$ was set at response variables (Phycocyanin yield and anti-oxidant activity-EC $\mathrm{E}_{50}$ ), with Equation 5:

$$
\begin{aligned}
& Y_{i}=\beta_{o}+\beta_{1} X_{1}+\beta_{2} X_{2}+\beta_{3} X_{3}+\beta_{12} X_{1} X_{2}+\beta_{13} X_{1} X_{3} \\
& +\beta_{23} X_{2} X_{3}+\beta_{11} X_{1}^{2}+\beta_{22} X_{2}^{2}+\beta_{33} X_{3}^{2}
\end{aligned}
$$

\section{Statistical analysis}

The Statistica 6.0 software was employed to analyze experimental data and to calculate the predicted response.
After the RSM optimization, the additional experiments were conducted to confirm and to verify the validity of the developed model equation as well as the statistical experimental design.

Moreover, the software was also facilitated to generate graph of predicted response values in $2-\mathrm{D}$ or $3-\mathrm{D}$ plots. The significance evaluation between the mean of phycocyanin concentrations in different experimental runs were statistically defined at $\mathrm{p}<0.05$.

\section{RESULT AND DISCUSSION}

\section{Extraction of phycocyanin under variation of UAE temperature and time}

The effects of UAE temperature to the extraction yield and $\mathrm{EC}_{50}$ were evaluated at the range temperature of $30^{\circ}$ to $60^{\circ} \mathrm{C}$ (Fig. 1). The results showed that optimum yield was obtained at the temperature of $45^{\circ} \mathrm{C}$ due to effects of irradiation generated by ultrasound. The cavitation can accelerate the extraction through cell wall disruption, and it also causes formation of voids in the structure of cell. Therefore, this can cause an increase in the mass transfer of phycocyanin from cell into the solvent. Sarada et al., (1999) stated that phycocyanin yield will increase by increasing temperature until it reaches an optimum level.

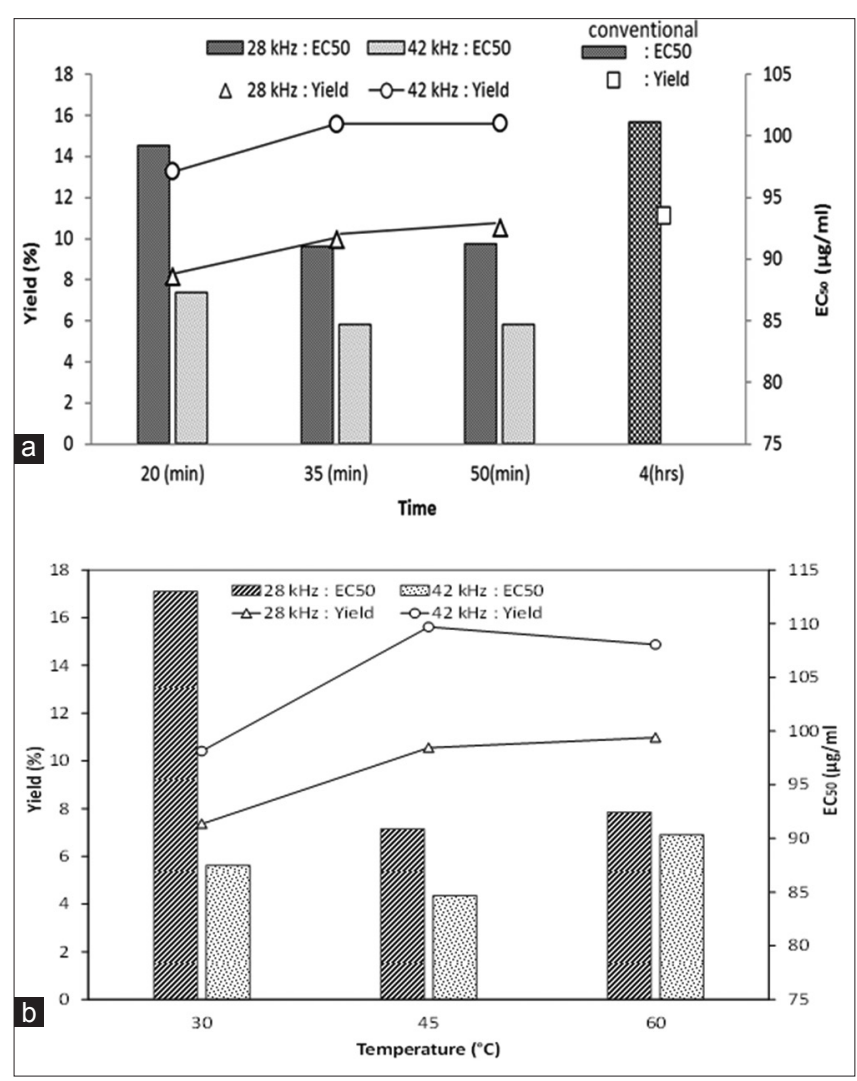

Fig 1. Yield and antioxidant activity $\left(\mathrm{EC}_{50}\right)$ profiles of phycocyanin extracted from Spirulina platensis as function of (a) extraction time and (b) UAE temperature 
Furthermore, we also observed that the yield decreased after the temperature rise to $60^{\circ} \mathrm{C}$. This is due to protein denaturation after temperature reaches $55^{\circ} \mathrm{C}$ (Sarada et al., 1999). Moreover, the increase of temperature more than optimum point will reduce the cavitation intensities (Dey and Rathod, 2013). Therefore, utilizing UAE temperature higher than $60^{\circ} \mathrm{C}$ will not improve the yield of phycocyanin and reduce the activity of antioxidant. At this temperature, molecular structure of phycocyanin will change due to coagulation.

Fig. 1 also shows that the extracted phycocyanin significantly is more effective in frequency of $42 \mathrm{kHz}$ when compared to the extraction at the frequency of $28 \mathrm{kHz}$. Higher the ultrasonic frequency can generate stronger cavitation effects during the extraction process thus increasing the mass transfer at the biomass-solvent surface. At the frequency of $28 \mathrm{kHz}$ the rate of diffusion of the solvent into the material is not optimal because the emitted frequency is only partially able to disrupt or break the cell wall from biomass. During extraction, two physical phenomena may involve: (1) diffusion of solvent through the cell walls and (2) washing out the cell contents after the cell wall were broken. These phenomena are very affected by the ultrasound irradiation (Vinatoru, 2001).

Model development for the prediction of phycocyanin The model paramaters of Eq 5 were statistically determined by using response surface methodology (RSM) based on a designed set of experiments data. The predicted model must be validated with set of experimental data to guarantee that the predicted model fits well to estimate the

\begin{tabular}{|c|c|c|c|c|c|c|c|c|c|c|}
\hline \multirow[t]{2}{*}{ Run } & \multirow{2}{*}{\multicolumn{3}{|c|}{$\begin{array}{l}\text { Code } \\
\text { pattern }\end{array}$}} & \multirow[t]{2}{*}{$\begin{array}{c}\text { Temp } \\
\left({ }^{\circ} \mathrm{C}\right)\end{array}$} & \multirow[t]{2}{*}{$\begin{array}{l}\text { Time } \\
(\min )\end{array}$} & \multirow[t]{2}{*}{$\begin{array}{l}\text { Freq } \\
(\mathrm{kHz})\end{array}$} & \multicolumn{2}{|c|}{$\begin{array}{l}\text { Experimental } \\
\text { values }\end{array}$} & \multicolumn{2}{|c|}{$\begin{array}{l}\text { Predicted } \\
\text { values }\end{array}$} \\
\hline & & & & & & & $\begin{array}{l}\text { Yield } \\
(\%)\end{array}$ & $\begin{array}{c}E C_{50} \\
(\mu \mathrm{g} / \mathrm{mL})\end{array}$ & $\begin{array}{l}\text { Yield } \\
(\%)\end{array}$ & $\begin{array}{c}E_{50} \\
(\mu \mathrm{g} / \mathrm{mL})\end{array}$ \\
\hline 1 & -1 & -1 & 0 & 30 & 20 & 35 & 5.95 & 114.15 & 5.60 & 114.79 \\
\hline 2 & 1 & -1 & 0 & 60 & 20 & 35 & 13.16 & 88.18 & 13.01 & 87.59 \\
\hline 3 & -1 & 1 & 0 & 30 & 50 & 35 & 8.88 & 100.26 & 9.03 & 100.86 \\
\hline 4 & 1 & 1 & 0 & 60 & 50 & 35 & 12.93 & 91.39 & 13.28 & 90.74 \\
\hline 5 & -1 & 0 & -1 & 30 & 35 & 28 & 6.38 & 120.15 & 5.94 & 119.03 \\
\hline 6 & 1 & 0 & -1 & 60 & 35 & 28 & 10.87 & 91.36 & 10.22 & 91.49 \\
\hline 7 & -1 & 0 & 1 & 30 & 20 & 42 & 7.71 & 100.20 & 8.36 & 100.07 \\
\hline 8 & 1 & 0 & 1 & 60 & 35 & 42 & 15.30 & 89.18 & 15.75 & 90.30 \\
\hline 9 & 0 & -1 & -1 & 45 & 20 & 28 & 8.16 & 99.21 & 8.96 & 99.68 \\
\hline 10 & 0 & 1 & -1 & 45 & 50 & 28 & 10.55 & 90.89 & 10.85 & 91.41 \\
\hline 11 & 0 & -1 & 1 & 45 & 20 & 42 & 13.27 & 87.25 & 12.97 & 86.73 \\
\hline 12 & 0 & 1 & 1 & 45 & 50 & 42 & 15.58 & 84.68 & 14.78 & 84.21 \\
\hline 13 & 0 & 0 & 0 & 45 & 35 & 35 & 12.85 & 88.19 & 12.77 & 88.35 \\
\hline 14 & 0 & 0 & 0 & 45 & 35 & 35 & 12.63 & 88.50 & 12.77 & 88.35 \\
\hline 15 & 0 & 0 & 0 & 45 & 35 & 35 & 12.82 & 88.35 & 12.77 & 88.35 \\
\hline
\end{tabular}

experimental data. Therefore, the model and experimental points must have high coefficient determination $\left(\mathrm{R}^{2}\right)$. From the analysis of variances for the experimental data (Table 2), it showed that $\mathrm{R}^{2}$ value of the model was 0.9772 which indicating that $97.72 \%$ of the experimental data can be fitted with the model predicted value of phycocyanin (Fig. 2). In addition, the coefficient determination $\left(\mathrm{R}^{2}\right)$ for predicted model of $\mathrm{EC}_{50}$ shows 0.9966 , meaning that $99.66 \%$ experimental data match well to the predicted data (Table 3).

The validity of the predicted model further were shown by its root mean square error (RMSE) to estimate the standard deviation of the random error (Vuong et al., 2015). Tables 2 and 3 also showed that RMSE of yield and EC50 was 0.448 and 0.583 , respectively. These low RMSE values confirmed that in the analyzed samples there is a linear correlation between the predicted and experimental contents of phycocyanin. The quality of measuring data was indicated by the Predicted Residual Sum of Squares (PRESS) of the predicted model. Zhang et al. (2009) defined the PRESS as a measure of how a chosen model fits each point in the design. Tables 2 and 3 show that the PRESS values were 3.01 and 5.1 for yield and $\mathrm{EC}_{50}$, respectively, indicating that the model has a good measure. In addition, the $\mathrm{p}$-value of the model parameters were mostly below than 0.05 , except for $\beta_{23}$ in yield model $(\mathrm{p}=0.769316)$ and $\beta_{22}$ in $\mathrm{EC}_{50}$ model $(\mathrm{p}=0.697287)$. These $\mathrm{p}$-values proofing that the developed model predictions parameters were significant (Zhang et al., 2009).

Moreover, the statistical analysis also show that it was not possible to assess the lack of fit due to many estimated parameters involved, which eventually confirmed that the model was very well fit to the second-order polynomial formula as defined in Equation 6 and 7 (Vuong et al., 2015).

Table 2: Estimated regression coefficients for the quadratic polynomial model of phycocyanin yield

\begin{tabular}{lcccc}
\hline Parameters & $\begin{array}{c}\text { Predicted } \\
\text { coefficients }\end{array}$ & $\begin{array}{c}\text { Standard } \\
\text { error }\end{array}$ & DF & p value \\
\hline$\beta_{0}$ & 12.76667 & 0.06888 & 1 & 0.000029 \\
$\beta_{1}$ & 2.9175 & 0.04218 & 1 & 0.000209 \\
$\beta_{2}$ & 0.925 & 0.04218 & 1 & 0.00207 \\
$\beta_{3}$ & 1.9875 & 0.04218 & 1 & 0.00045 \\
$\beta_{12}$ & -0.79 & 0.059652 & 1 & 0.005653 \\
$\beta_{13}$ & 0.775 & 0.059652 & 1 & 0.005872 \\
$\beta_{23}$ & -0.02 & 0.059652 & 1 & $0.769316(p>0.05)$ \\
$\beta_{11}$ & -2.1808 & 0.062088 & 1 & 0.00081 \\
$\beta_{22}$ & -0.35583 & 0.062088 & 1 & 0.029122 \\
$\beta_{33}$ & -0.5208 & 0.062088 & 1 & 0.01392 \\
Lack of fit & & & 3 & \\
Pure error & & & & \\
$R^{2}$ & 0.9772 & & Adj R & 0.936 \\
PRESS & 3.01 & & RMSE & 0.448 \\
\hline
\end{tabular}


For yield

$$
\begin{aligned}
& Y_{i}=12.767+2.9175 X_{1}+0.925 X_{2}+1.9875 X_{3} \\
&-0.79 X_{1} X_{2}+0.775 X_{1} X_{3}-0.02 X_{2} X_{3}+ \\
&-2.1808 X_{1}^{2}-0.35583 X_{2}^{2}-0.5208 X_{3}^{2}
\end{aligned}
$$

For antioxidant activity $\left(\mathrm{EC}_{50}\right)$

$$
\begin{aligned}
\mathrm{Y}_{\mathrm{i}}= & 88.34667-9.33125 \mathrm{X}_{1}-2.69626 \mathrm{X}_{2}-5.0375 \mathrm{X}_{3}+ \\
& 4.27375 \mathrm{X}_{1} \mathrm{X}_{2}+4.4425 \mathrm{X}_{1} \mathrm{X}_{3}+1.4375 \mathrm{X}_{2} \mathrm{X}_{3}+ \\
& 9.91367 \mathrm{X}_{1}^{2}+0.21667 \mathrm{X}_{2}^{2}+1.94417 \mathrm{X}_{3}^{2}
\end{aligned}
$$

\section{Effects of UAE parameters on yield and $\mathrm{EC}_{50}$}

The effects of the three UAE parameters on extraction yield and $\mathrm{EC}_{50}$ of phycocyanin were investigated. The results (Figs. 3 and 4) showed that temperature in UAE process was a significant parameter, with increasing temperature corresponding to a higher yield and higher antioxidant activity(lower $\mathrm{EC}_{50}$ values). At a constant conditions of $38 \mathrm{~min}$ and frequency at $38 \mathrm{kHz}$, the phycocyanin yield increased from $8 \%$ to $13.85 \%$ across a temperatures ranging between 30 and $60 \circ \mathrm{C}$, while the phycocyanin antioxidant $\left(\mathrm{EC}_{50}\right)$ decreased from $108 \mu \mathrm{g} / \mathrm{mL}$ to $86.1 \mu \mathrm{g} / \mathrm{mL}$.

Table 2 shows a p-value of 0.000209 for temperature indicating the significance of temperature on extraction yield, while the significance effects of temperature is also shown on $\mathrm{EC}_{50}(\mathrm{p}=0.000002)$ (Table 3). The significance effect of temperature to extraction of bioactive compound has also been shown in euphenol extraction from Euphorbia tirucalli (Vuong et al., 2015), phenolic compounds from the seed cake extracts (Teh and Birch, 2014), trans-lycopene from red grapefruit (Xu and Pan, 2013). These studies reported that the use of higher temperature resulted higher yields of bioactive compounds since higher frequency would enhance the solubility of bioactive compounds, and consequently destroying the plant tissue to liberate the bioactive compounds (Teh and Birch, 2014).

Table 2 also shows that UAE time significantly affected the extraction yield of phycocyanin $(\mathrm{p}=0.000646)$. Under fixed conditions of temperature $\left(55^{\circ} \mathrm{C}\right)$ and UAE frequency $(38 \mathrm{kHz}$ ), the yields of phycocyanin were revealed to increase from $12.5 \%(\mathrm{~g} / \mathrm{g})$ to $13.85 \%(\mathrm{~g} / \mathrm{g})$ for extraction times between 20 and $38 \mathrm{~min}$. After $38 \mathrm{~min}$, flat trend of the yield was shown, implying that extended sonication would not gain further increase of extraction yield. Sahin and Samli (2013) claimed that the liberation of bioactive compound from plant material involving two consecutive processes: washing, in which plant material is quickly solubilized and slow extraction, where slower diffusion of bioactive compound occurs.
Phycocyanin activity was indicated by its value of $\mathrm{EC}_{50}$. The UAE time also has significant effect $(\mathrm{p}=0.000646)$ to the $\mathrm{EC}_{50}$. At constant conditions of temperature $55^{\circ} \mathrm{C}$ and frequency of $38 \mathrm{kHz}$, the $\mathrm{EC}_{50}$ slightly decreased from 88.2 to $86.1 \mu \mathrm{g} / \mathrm{mL}$ (Fig. 4).

In addition, Tables 2 and 3 also showed that extraction yield and phycocyanin activity $\left(\mathrm{EC}_{50}\right)$ were significantly affected by UAE frequencies $(\mathrm{p}=0.00045$ for yield, $\mathrm{p}=0.000032$ for $\mathrm{EC}_{50}$, respectively). Under fixed conditions of temperature $\left(55^{\circ} \mathrm{C}\right)$ and time $(38 \mathrm{~min})$, the yield of phycocyanin increased from $10 \%(\mathrm{~g} / \mathrm{g})$ to $13.85 \%(\mathrm{~g} / \mathrm{g})$ as UAE frequency increased from 28 to $38 \mathrm{kHz}$. At the same condition, the EC50 decreased from $95 \mu \mathrm{g} / \mathrm{mL}$ to $86.1 \mu \mathrm{g} / \mathrm{mL}$ by increasing frequency, indicating that the anti-oxidant is more active at higher ultrasound frequencies (Fig. 4).

\section{Optimization of ultrasonic conditions for UAE of phycocyanin}

The linear regression models obtained from Eqs 6 and 7 were used to determine optimum values of extraction temperature, UAE time and UAE frequencis by using optimization procedures. The objective function $(J)$ in this optimization was defined to minimize simultaneously the $\mathrm{EC}_{50}$ as well as to maximize the yield of phycocyanin extract with subject to temperature range $\left(\mathrm{X}_{1}\right)$, UAE time $\left(\mathrm{X}_{2}\right)$, and UAE frequency $\left(\mathrm{X}_{3}\right)$.

$$
\begin{aligned}
& \min J=-Y_{\text {yield }}+Y_{\mathrm{EC} 50} \\
& Y=f\left(X_{1}, X_{2}, X_{3}\right) \\
& -1 \leq X_{1} \leq 1 \\
& -1 \leq X_{2} \leq 1 \\
& -1 \leq X_{3} \leq 1
\end{aligned}
$$

Table 3: Estimated regression coefficients for the quadratic polynomial model of phycocyanin antioxidant activity $\left(\mathrm{EC}_{50}\right)$

\begin{tabular}{lcccc}
\hline Parameters & $\begin{array}{c}\text { Predicted } \\
\text { coefficients }\end{array}$ & $\begin{array}{c}\text { Standard } \\
\text { error }\end{array}$ & DF & p value \\
\hline$\beta_{0}$ & 88.34667 & 0.583175 & 1 & 0.000000 \\
$\beta_{1}$ & -9.33125 & 0.357120 & 1 & 0.000002 \\
$\beta_{2}$ & -2.69625 & 0.357120 & 1 & 0.000646 \\
$\beta_{3}$ & -5.03750 & 0.357120 & 1 & 0.000032 \\
$\beta_{12}$ & 4.27375 & 0.505044 & 1 & 0.000378 \\
$\beta_{13}$ & 4.44250 & 0.505044 & 1 & 0.000315 \\
$\beta_{23}$ & 1.43750 & 0.505044 & 1 & 0.035980 \\
$\beta_{11}$ & 9.93188 & 0.525667 & 1 & 0.000008 \\
$\beta_{22}$ & 0.21667 & 0.525667 & 1 & $0.697287(p>0.05)$ \\
$\beta_{33}$ & 1.94417 & 0.525667 & 1 & 0.000032 \\
Lack of fit & & & 3 & \\
Pure error & & & & \\
$R^{2}$ & 0.9966 & & Adj R & 0.9904 \\
PRESS & 5.1 & & RMSE & 0.583 \\
\hline
\end{tabular}




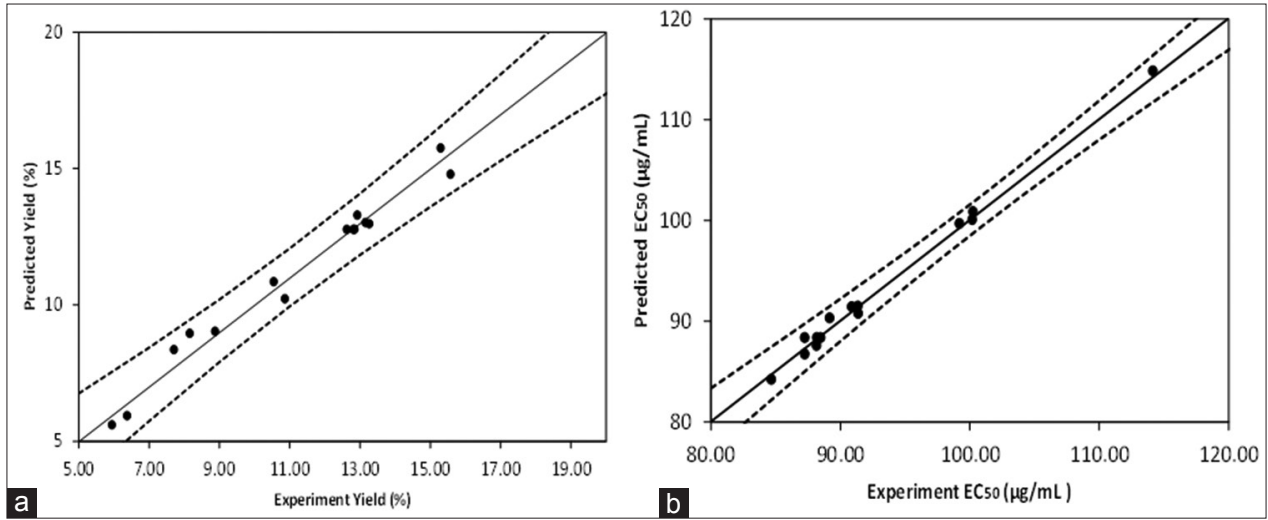

Fig 2. Correlation between the predicted and actual values of (a) phycocyanin yield $\left(R^{2}=0.9772\right)$ and (b) antioxidant activity-EC $C_{50}\left(R^{2}=0.9966\right)$

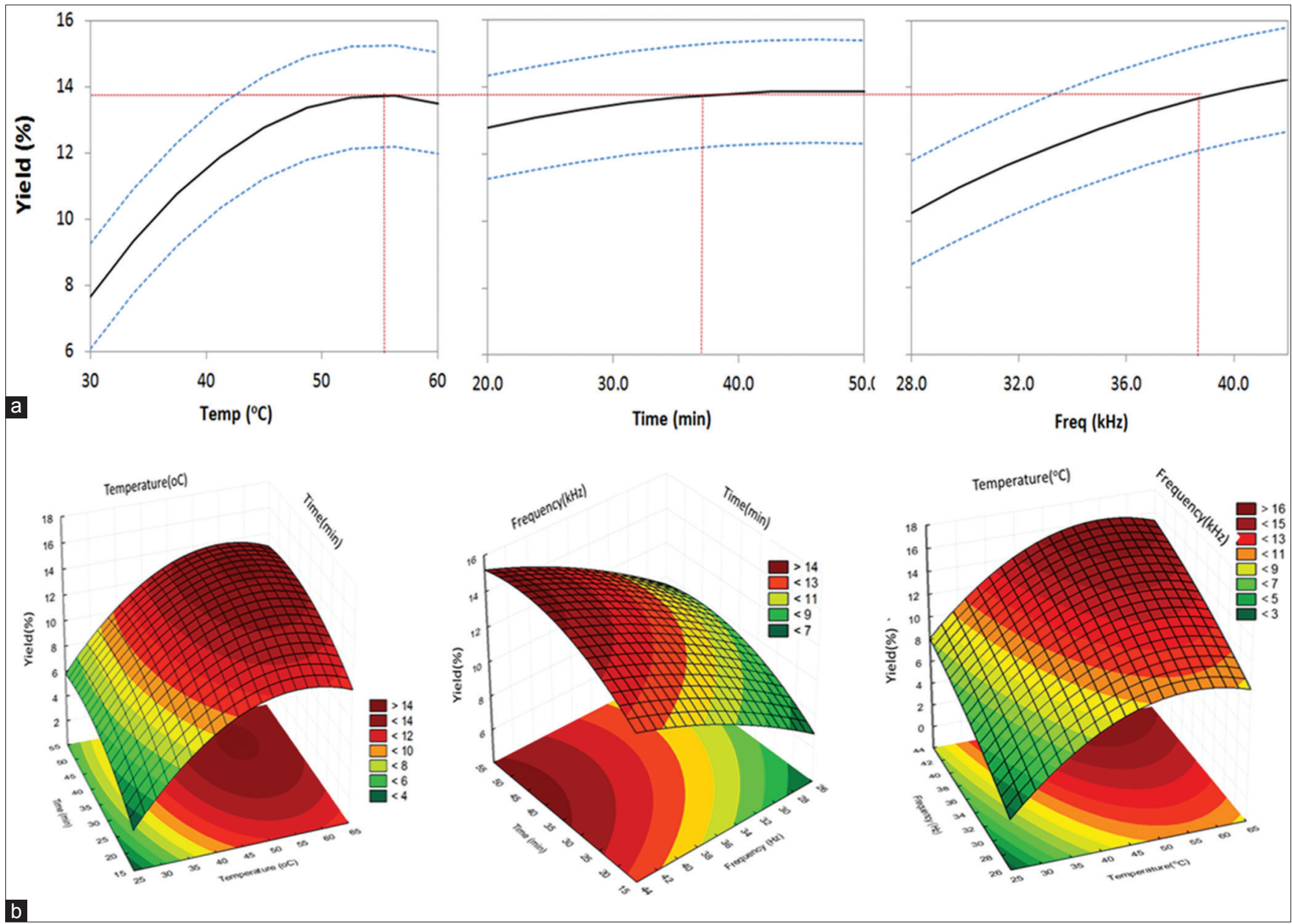

Fig 3. Effect of UAE temperature, time and frequency on the extraction yield of phycocyanin (a); and the 3D and 2D response surfaces profiles of phycocyanin yield as affected by independent variables (b).

From this optimization procedure, the optimum value of temperature $\left(\mathrm{X}_{1}\right.$,op: $)$, UAE time $\left(\mathrm{X}_{2}\right.$,opt $)$, and UAE frequency $\left(\mathrm{X}_{3}{ }^{\text {oppt }}\right)$ will be gained. Using these optimum parameters, the yield and $\mathrm{EC}_{50}$ optimum were recalculated by using Eq 6 and 7. The additional experiments at the optimum conditions were carried out to confirm the predicted yield and EC50.
The optimization showed that the optimum conditions of UAE were $\mathrm{X}_{1}=0.471, \mathrm{X}_{2}=0.4154$ and $\mathrm{X}_{3}=1$, which represented the real conditions of temperature $=52.5^{\circ} \mathrm{C}$, UAE time $=42 \mathrm{~min}$ and UAE frequency of $42 \mathrm{kHz}$. The results are indicating that to gain maximum yield, the UAE must be set at maximum frequency, while the temperature and time can be lower than the maximum defined variables. 


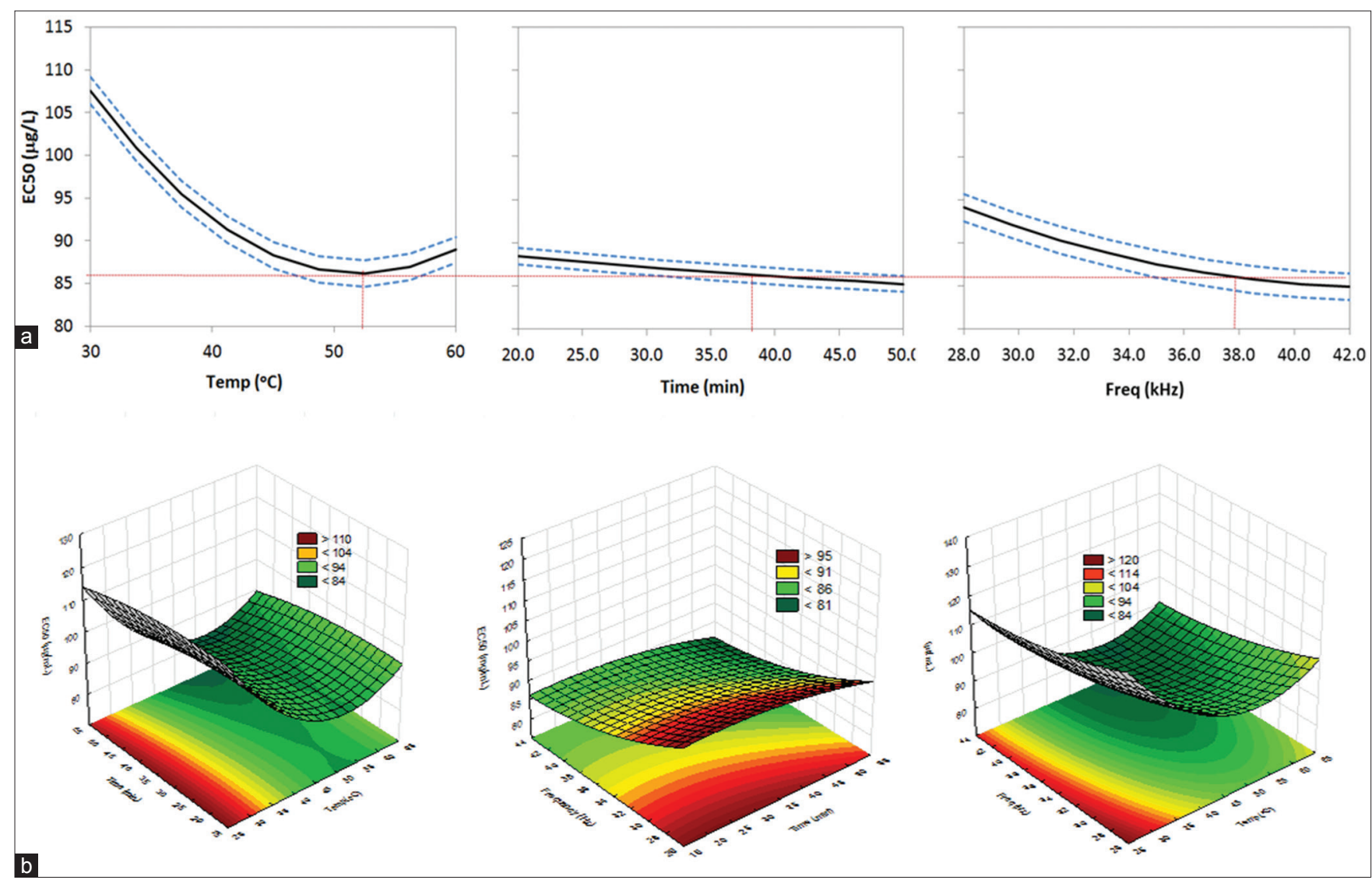

Fig 4. Impact of ultrasonic temperature, time and frequency on the antioxidant activity-EC Fo $_{0}$ of phycocyanin (a); and the 3D and 2D response surfaces profiles of phycocyanin EC50 as affected by independent variables (b).

Table 4: The optimum values of yield and $\mathrm{EC}_{50}$ which were obtained by optimization of Eq 6-7

\begin{tabular}{|c|c|c|c|c|}
\hline \multirow[t]{2}{*}{ Variables } & \multicolumn{2}{|c|}{ Optimum conditions $\left(\mathrm{X}_{\mathrm{opt}}\right)$} & \multicolumn{2}{|c|}{ Value of respond $\left(\mathrm{Y}_{\mathrm{opt}}\right)$} \\
\hline & Coded & Real value & Predicted & Experiment \\
\hline Temperature & 0.471 & $52.5\left({ }^{\circ} \mathrm{C}\right)$ & Yield $=15.7 \%(\mathrm{~g} / \mathrm{g})$ & Yield $=(14.94 \pm 0.21) \%(\mathrm{~g} / \mathrm{g})$ \\
\hline Time & 0.4154 & $42(\min )$ & $\mathrm{EC}_{50}=85.78 \mathrm{mg} / \mathrm{mL}$ & $\mathrm{EC}_{50}=(86.3 \pm 1.65) \mathrm{mg} / \mathrm{mL}$ \\
\hline Frequency & 1 & $42(\mathrm{kHz})$ & & \\
\hline
\end{tabular}

The experimental values were obtained from the experiment at the optimum process conditions

At optimal UAE conditions, the developed model predicted a phycocyanin yield of $15.7 \% \mathrm{~g} / \mathrm{g}$ of algae biomass and EC50 $85.78 \mathrm{mg} / \mathrm{mL}$. To verify this prediction, the additional extraction experiment for algae biomass was carried out under optimal conditions $(\mathrm{n}=3)$. The experimental results (Table 4) showed that a phycocyanin yield of $(14.94 \pm 0.21) \% \mathrm{~g} / \mathrm{g}$ and $\mathrm{EC}_{50}$ of $(86.3 \pm 1.65) \mathrm{mg} / \mathrm{mL}$ which were revealed to be within tolerances of the predicted value $(\mathrm{p}>0.05)$, therefore it validated the predicted model.

\section{CONCLUSION}

The extraction of phycocyanin assisted by ultrasound irradiation and its optimization has been studied for Spirulina platensis. Ultrasonic irradiation was an efficient tool to improve the performance of phycocyanin extraction through optimization techniques by using response surface methodology (RSM). The results presented that UAE temperature, UAE time and ultrasound frequency had significant influences on the yield and anti-oxidant activity $\left(\mathrm{EC}_{50}\right)$ of phycocyanin. The optimum process conditions were extraction for $42 \mathrm{~min}$ at $52.5^{\circ} \mathrm{C}$ under ultrasound frequency of $200 \mathrm{~W}$. Under these optimal conditions, the yield of phycocyanin was $15.7 \%(\mathrm{~g} / \mathrm{g})$ and $\mathrm{EC}_{50}$ was $85.78 \mu \mathrm{g} / \mathrm{mL}$.

\section{ACKNOWLEDGEMENTS}

We gratefully thank Institute of Research and Community Services (LPPM) Diponegoro University for supporting the project through Riset Unggulan Universitas (RUU) 2015. 


\section{Author contribution}

H.H.: Main researcher, collected data, analyzed the data and wrote article. SS.: Associate, Supported in providing literature, data collection, and analysis.

\section{REFERENCES}

Antelo, F. S., J. A. V. Costa and S. J. Kalil. 2008. Thermal degradation kinetics of the phycocyanin from Spirulina platensis. Biochem. Eng. J. 41: 43-47.

Box, G. and K. Wilson. 1951. On the experimental attainment of optimum conditions. J. R. Stat. Soc. 13: 1-45.

Chaiklahan, R., N. Chirasuwan and B. Bunnag. 2012. Stability of phycocyanin extracted from Spirulina $\mathrm{sp}$ : Influence of temperature, $\mathrm{pH}$ and preservatives. Process Biochem. 47(4): 659-664.

Dey, S. and V. K. Rathod. 2013. Ultrasonics sonochemistry ultrasound assisted extraction of $\mathrm{b}$ - carotene from Spirulina platensis. Ultrason. Sonochem. 20(1): 271-276.

Gunjan, H. and B. Tasneem. 2011. Studies on Anabaena sp . NCCU9 with special reference to phycocyanin. J. Algal Biomass UtIn. 2(1): 30-51.

Hadiyanto, Suttrisnorhadi, H. Sutanto, M. Suzery, D. Soetrisnanto and N. Azizah. 2015. The effects of temperature and frequencies in ultrasound assisted extraction of phycocyanin from microalgae Spirulina sp, AIP Conference Proceedings. p1699, 030009.

Hardlei, T. F., A. L. Morkbak and E. Nexo. 2007. Enzymatic extraction of cobalamin from monoclonal antibody captured haptocorrin and transcobalamin. Clin. Biochem. 40: 1392-1397. DOI: 10.1016/j.clinbiochem.2007.09.008.

Ibañez, E., M. Herrero, J. A. Mendiola and M. Castro-puyana. 2012. Extraction and characterization of bioactive compounds with health benefits. In: Hayes, M., (Ed.), Marine Resources : Macro and Micro Algae, Cyanobacteria, and Invertebrates Bioactive Compounds from Marine Sources, Springer Science, Berlin, Germany, Pp. 55-98. DOI: 10.1007/978-1-4614-1247-2.

Kadam, S. U., B. K. Tiwari, T. J. Smyth and C. P. O'Donnell. 2015. Optimization of ultrasound assisted extraction of bioactive components from brown seaweed Ascophyllum nodosum using response surface methodology. Ultrason. Sonochem. 23: 308-316.

Kuddus, M., P. Singh, G. Thomas and A. Al-Hazimi. 2013. Recent developments in production and biotechnological applications of C-phycocyanin. Biomed. Res. Int. 2013: 742859. DOI: 10.1155/2013/742859.

Maria, A., P. Neto, R. Augusto, S. Souza, A. D. De, Leon-nino, D. Joana and F. Gianesella. 2013. Improvement in microalgae lipid extraction using a sonication-assisted method. Renewable Energy. 55: 525-531.

Moraes, C. C., L. Sala, G. P. Cerveira and S. J. Kalil. 2011. C-phycocyanin extraction from Spirulina platensis wet biomass. Braz. J. Chem. Eng. 28(1): 45-49.

Oliveira, E. G., J. H. Duarte, K. Moraes, V. T. Crexi and L. A. A. Pinto. 2010. Optimisation of Spirulina platensis convective drying: Evaluation of phycocyanin loss and lipid oxidation. Int. J. Food Sci. Technol. 45: 1572-1578.

Romay, C. H., R. González, N. Ledón, D. Remirez and V. Rimbau. 2003. C-phycocyanin: A biliprotein with antioxidant, anti- inflammatory and neuroprotective effects. Pharmacol. Res. Sci. 4: 207-216.

Rostagno, M. A., M. Palma and C. G. Barroso. 2003. Ultrasoundassisted extraction of soy isoflavones. J. Chromatogr. A. 1012: 119-128. DOI: 10.1016/S0021-9673(03)01184-1.

Sahin, S. and R. Samli. 2013. Optimization of olive leaf extract obtained by ultrasound assisted extraction with response surface methodology. Ultrason. Sonochem. 20: 595-602.

Sarada, R., M. G. Pillai and G. A. Ravishankar. 1999. Phycocyanin from Spirulina sp: influence of processing of biomass on phycocyanin yield, analysis of efficacy of extraction methods and stability studies on phycocyanin. Process Biochem. 34: 795-801.

Schwede, S., A. Kowalczyk, M. Gerber and R. Span. 2011. Influence of different cell disruption techniques on mono digestion of algal biomass. Bioenergy Technology Section of World Renewable Energy Congress, 8-13 May Sweden, Pp. 1-2.

Shirsath, S. R., S. H. Sonawane and P. R. Gogate. 2012. Chemical engineering and processing: Process intensification intensification of extraction of natural products using ultrasonic irradiations - A review of current status. Chem. Eng. Process. 53: $10-23$

Sivasankari, S., and D. Ravindran. 2014. Comparison of different extraction methods for phycocyanin extraction and yield from Spirulina platensis. Int. J. Curr. Microbiol. Appl. Sci. 3(8): 904-909.

Teh, S. S. and E. J. Birch. 2014. Effect of ultrasonic treatment on the polyphenol content and antioxidant capacity of extract from defatted hemp, flax and canola seed cakes. Ultrason. Sonochem. 21: 346-353.

Setyoningrum,T. M. and M. M. A. Nur. 2015. Optimization of C-phycocyanin production from $\mathrm{S}$. platensis cultivated on mixotrophic condition by using response surface methodology. Biocatal. Agric. Biotechnol. 4: 603-607.

Vilkhu, K., R. Mawson, L. Simons and D. Bates. 2008. Applications and opportunities for ultrasound assisted extraction in the food industry - A review. Innov. Food Sci. Emerg. Technol. 9: 161-169.

Vinatoru, M. 2001. An overview of the ultrasonically assisted extraction of bioactive principles from herbs. Ultrason. Sonochem. 8: 303-313.

Vuong, Q. V., J. B. Golding, M. H. Nguyen and P. D. Roach. 2012. Production of caffeinated and decaffeinated green tea catechin powders from underutilised old tea leaves. J. Food Eng. 110: 1-8.

$\mathrm{Xu}, \mathrm{Y}$. and S. Pan. 2013. Effects of various factors of ultrasonic treatment on the extraction yield of all-trans-lycopene from red grapefruit (Citrus paradise Macf.). Ultrason. Sonochem. 20: 1026-1032.

Yang, H., X. Li, Y. Tang, N. Zhang, J. Chen and B. Cai. 2009. Supercritical fluid $\mathrm{CO} 2$ extraction and simultaneous determination of eight annonaceous acetogenins in Annona Genus plant seeds by HPLC-DAD method. J. Pharm. Biomed. Anal. 49: 140-144. DOI: 10.1016/j.jpba.2008.09.055.

Yeh, J. Y., L. H. Hsieh, K. T. Wu and C. F. Tsai. 2011. Antioxidant properties and antioxidant compounds of various extracts from the edible Basidiomycete Grifola Frondosa (Maitake). Molecules. 16: 3197-3211.

Zhang, Q. A., Z. Q. Zhang, X. F. Yue, X. H. Fan, T. Li S. F. Chen. 2009. Response surface optimization of ultrasound-assisted oil extraction from autoclaved almond powder. Food Chem. 116: 513-518. 